\title{
Follicular dynamics, circulating progesterone, and fertility in Holstein cows synchronized with reused intravaginal progesterone implants that were sanitized by autoclave or chemical disinfection
}

\author{
L. F. Melo,, ${ }^{\text {P. L. J. Monteiro Jr., }{ }^{*} \text { A. B. Nascimento, } † ~ J . ~ N . ~ D r u m, ~}{ }^{*}$ C. Spies, ${ }^{*}$ A. B. Prata, ${ }^{*}$ M. C. Wiltbank,‡ \\ and $R$. Sartori ${ }^{* 1}$ \\ *Department of Animal Science, University of São Paulo, Piracicaba, SP 13418-900, Brazil \\ †Department of Technical Services, ABS Global Inc., De Forest, WI 53532 \\ ‡Department of Dairy Science, University of Wisconsin-Madison, Madison 53706
}

\begin{abstract}
This experiment aimed to compare circulating progesterone (P4), follicular dynamics, and fertility during reuse of intravaginal $\mathrm{P} 4$ implants that were sanitized by autoclave or chemical disinfection in lactating Holstein cows submitted to fixed-time artificial insemination (FTAI). For this, 123 primiparous and 226 multiparous cows from 2 farms, averaging (mean \pm standard deviation) $163.9 \pm 141.9 \mathrm{~d}$ in milk, $35.7 \pm 11.3 \mathrm{~kg}$ of milk $/ \mathrm{d}$, and a body condition score of $2.9 \pm 0.5$, were enrolled in the study. Cows were randomly assigned to 1 of 2 treatments using a completely randomized design and each cow received a reused implant (1.9 g of P4; previously used for $8 \mathrm{~d}$ ) that was either autoclaved (AUT; n $=177)$ or chemically disinfected (CHEM; $\mathrm{n}=172)$ on $\mathrm{d}-10$. Also on $\mathrm{d}-10$, cows received $2 \mathrm{mg}$ of estradiol benzoate and $100 \mu \mathrm{g}$ of GnRH. On d -3, cows received $25 \mathrm{mg}$ of dinoprost $\left(\mathrm{PGF}_{2 \alpha}\right)$. A second $\mathrm{PGF}_{2 \alpha}$ was given on $\mathrm{d}-2$, along with $1 \mathrm{mg}$ of estradiol cypionate and P4 implant removal. Cows received FTAI on d 0. A subset of cows $(\mathrm{n}=143)$ was evaluated by ultrasound on $\mathrm{d}-10,-8,-6,-3,-2,0$, and 5 to identify ovarian structures, and blood was sampled on $\mathrm{d}-10,-3$, and -2 for P4 concentrations by RIA. Pregnancy diagnoses were performed at d 32 and 60 . Statistical analyses was performed using PROC-MIXED for continuous variables and PROC-GLIMMIX of SAS 9.4 (SAS Institute Inc., Cary, NC) for binomial variables. The treatments did not differ in circulating $\mathrm{P} 4$ on $\mathrm{d}-10$ or -3 , but $\mathrm{P} 4$ was greater on $\mathrm{d}-2$ in CHEM cows. Ovulation to the treatments on $\mathrm{d}-10$ was associated with lower circulating $\mathrm{P} 4$ on $\mathrm{d}-10$ (2.0 vs. $3.1 \mathrm{ng} / \mathrm{mL})$ and resulted in greater $\mathrm{P} 4$ on $\mathrm{d}-3(4.0$ vs. $2.4 \mathrm{ng} / \mathrm{mL})$ and more cows with a corpus luteum on $d-3$ (100 vs. 40\%)
\end{abstract}

Received July 25, 2017.

Accepted December 5, 2017.

${ }^{1}$ Corresponding author: robertosartori@usp.br than nonovulating cows. Cows that ovulated to $\mathrm{d}-10$ treatments were more likely to have a synchronized new follicular wave (97.9 vs. $63.2 \%$ ) and had an earlier wave emergence (1.9 vs. $2.6 \mathrm{~d}$ ), resulting in less cows ovulating a persistent follicle (0.0 vs. 35.7\%). Type of P4 implant, corpus luteum presence on $\mathrm{d}-10$, and ovulation to $\mathrm{d}-10$ treatments did not affect fertility (pregnancy per AI; P/AI). However, P/AI on farm A was greater than on farm B at $32(40.8$ vs. $27.8 \%)$ and $60 \mathrm{~d}$ (35.8 vs. 24.3\%), independent of treatment. In conclusion, $\mathrm{P} 4$ implants with different $\mathrm{P} 4$ release patterns did not produce detectable differences in follicular dynamics, synchronization rate, or P/AI. Nevertheless, presence of corpus luteum or ovulation at the beginning of the FTAI protocol affected reproductive variables, such as timing and synchronization of follicular wave emergence, and size of the ovulatory follicle. Beyond that, more overall synchronized cows became pregnant to the FTAI protocol.

Key words: hormone, synchronization, device, Bos taurus

\section{INTRODUCTION}

Fixed-time artificial insemination (FTAI) programs are widely used worldwide and represent an important reproductive management tool to improve reproductive efficiency and profitability of commercial dairy herds (Norman et al., 2009). Although many dairies use AI as a way to improve the genetics of their herds with the use of proven sires (Vishwanath, 2003), challenges exist for maintaining good reproductive performance due to reduced detection of estrus (Washburn et al., 2002; Lopez et al., 2004) and declining pregnancies per AI (P/AI; Butler, 2000; Lucy, 2001; Washburn et al., 2002). The use of FTAI programs can reduce labor for managing AI by precisely synchronizing ovulation and have contributed to improvements in reproductive indexes (Wiltbank and Pursley, 2014). 
Since the first reported FTAI protocol was developed (Pursley et al., 1995), several modifications and improvements have been documented (Binelli et al., 2014; Wiltbank and Pursley, 2014); however, the main objectives continue to be the same: (1) synchronization of follicle wave emergence; (2) synchronization of corpus luteum (CL) function and circulating progesterone (P4); and (3) synchronization of final ovulation with optimally scheduled FTAI. To achieve these objectives, 2 major types of pharmaceutical approaches are available: (1) GnRH-based protocols, which use a combination of GnRH analogs at the beginning and at the end of the protocol, followed by 1 (Pursley et al., 1995; Souza et al., 2008) or 2 (Brusveen et al., 2009; Wiltbank et al., 2015) $\mathrm{PGF}_{2 \alpha}$ treatments; and (2) estradiol (E2)/P4-based protocols, which use a combination of $\mathrm{P} 4 /$ progestin and E2 esters, usually estradiol benzoate (EB), at the start of the protocol and 1 (Pereira et al., 2013a,b) or $2 \mathrm{PGF}_{2 \alpha}$ treatments (Binelli et al., 2014; Pereira et al., 2015). These protocols also use E2 esters, EB or estradiol cypionate (EC), to synchronize ovulation at the end of the protocol.

These 2 types of hormonal protocols have different advantages and disadvantages. Treatment with $\mathrm{GnRH}$ at the beginning of the GnRH-based protocols can induce ovulation of the dominant follicle, if present, leading to initiation of a new follicular wave and formation of a new CL, potentially increasing circulating $\mathrm{P} 4$ concentrations during development of the preovulatory follicle wave (Pereira et al., 2015). However, many studies have reported that $50 \%$ or fewer dairy cows ovulate when $\mathrm{GnRH}$ is given at a random stage of the estrous cycle (Giordano et al., 2012b; Bilby et al., 2013; Bisinotto et al., 2013; Lopes et al., 2013, Melo et al., 2016). Lack of ovulation to the initial GnRH treatment leads to less than optimal follicle wave synchronization and fertility. On the other hand, the combination of $\mathrm{P} 4$ and $\mathrm{E} 2$ at the beginning of the protocol in E2/ $\mathrm{P} 4$-based protocols leads to a suppression in secretion of gonadotropins (FSH and $\mathrm{LH}$ ), causing regression of the follicles in the current follicular wave (Burke et al., 1996; Bó et al., 2002; Cavalieri et al., 2003) and initiation of a new follicular wave 3 to 5 d later. Although the protocol can be initiated at any stage of the estrous cycle, almost $30 \%$ of the cows do not have emergence of a new follicular wave after the initial E2/P4 treatment, leading to ovulation of a larger persistent follicle at the end of the protocol, which produces lower fertility (Monteiro et al., 2015).

To offset these problems, a combination of GnRH with E2/P4 treatments at the initiation of the FTAI protocol has been evaluated with the encouraging observation of improved fertility in lactating dairy cows submitted to a protocol that lasted $11 \mathrm{~d}$ and had 2 treatments with $\mathrm{PGF}_{2 \alpha}$ at the end of the protocol (Pereira et al., 2015). However, this initial study did not evaluate the follicular dynamics during the protocol and, in particular, whether ovulation of persistent follicles was avoided with this approach. Moreover, the ovarian physiological responses of cows treated with GnRH plus E2/P4 at the beginning of a protocol has not been tested, especially when using intravaginal inserts with distinct $\mathrm{P} 4$ release patterns.

Several researchers have reported the importance of adequate concentrations of $\mathrm{P} 4$ during preovulatory follicle development, particularly in FTAI programs (Diskin et al., 2006; Stevenson et al., 2006, 2008; Chebel et al., 2010; Cerri et al., 2011a,b; Bilby et al., 2013; Bisinotto et al., 2013). Depending on circulating P4 concentrations, the pattern of follicle development can be modified, and low circulating P4 during the growth of the ovulatory follicle is often associated with lower fertility in lactating dairy cows undergoing a FTAI protocol (Cerri et al., 2011b). Low concentration of $\mathrm{P} 4$ allows for increased LH pulse frequency, which could extend follicular dominance (Savio et al., 1993), compromise oocyte quality, possibly due to premature resumption of meiosis (Revah and Butler, 1996; Inskeep, 2004), and, consequently, reduce fertility (Cunha et al., 2008; Bisinotto et al., 2010). Adequate circulating P4 during development of the ovulatory follicle is particularly important in the nearly $30 \%$ of dairy cows that are anovular or lack a CL at the beginning of the FTAI protocol (Stevenson et al., 2008; Santos et al., 2009; Melo et al., 2016). In these cows, the risk of becoming pregnant is reduced by $30 \%$ (Bisinotto et al., 2010).

For the purposes of our physiological studies, we chose to compare the autoclaved versus chemically disinfected, reused 1.9-g P4 implants because of the dramatic differences in the $\mathrm{P} 4$ profile throughout the 8 -d treatment period, as shown in our previous study (Melo et al., 2018). In this previous study, the average circulating $\mathrm{P} 4$ was greater $(P<0.05)$ for the autoclaved, reused controlled internal drug release (CIDR; $1.67+$ $0.06 \mathrm{ng} / \mathrm{mL})$ than the new CIDR $(1.49+0.07)$, and both were greater than the chemically disinfected CIDR $(1.21+0.05)$. Thus, we hypothesized that the greater circulating $\mathrm{P} 4$ that results from using autoclaved compared with chemically disinfected P4 implants would alter the patterns of follicle growth and these changes would be associated with an improvement in fertility. Thus, our objectives were to compare circulating P4, ovarian dynamics, and fertility in lactating dairy cows treated with reused 1.9-g intravaginal P4 implants that were previously autoclaved or chemically disinfected as part of an FTAI protocol that combined GnRH and EB treatment at the beginning of the protocol. 


\section{MATERIALS AND METHODS}

This experiment was conducted in 2 commercial dairy farms. The Animal Research Ethics Committee of Escola Superior de Agricultura "Luiz de Queiroz"/ University of São Paulo approved all procedures involving cows in this study.

\section{Cows, Housing, and Diets}

For this study, 349 lactating Holstein cows were used (123 primiparous and 226 multiparous). At the beginning of the experiment $(\mathrm{d}-10)$, cows averaged (mean $\pm \mathrm{SD}) 163.9 \pm 141.86$ DIM, yielding $35.7 \pm 11.31 \mathrm{~kg}$ of milk/d, with BCS of $2.9 \pm 0.47$ (Ferguson et al., 1994), lactation number of $2.3 \pm 1.37$, and AI number of $2.4 \pm 3.08$ (approximately $35 \%$ of AI were first postpartum AI, and $\sim 30 \%$ of the cows enrolled were treated only once). At farm A, 161 cows were enrolled (55 primiparous and 106 multiparous) and averaged at the beginning of the experiment (mean \pm SD) $127.8 \pm$ 96.63 DIM, yielding $40.5 \pm 10.21 \mathrm{~kg}$ of milk/d, with BCS of $2.9 \pm 0.50$, lactation number of $2.2 \pm 1.32$, and AI number of $1.52 \pm 1.96$. Cows were housed in a crossventilated freestall barn with free access to water and mineral salt and fed ad libitum with a TMR diet based on corn silage and Tifton 85 hay as forages, concentrate based on corn and soybean meal, and minerals and vitamins balanced to meet or exceed the nutritional requirements of lactating dairy cows (NRC, 2001). At farm B, 188 cows were enrolled (68 primiparous and 120 multiparous) and averaged at the beginning of the experiment (mean \pm SD) 195.6 \pm 166.00 DIM, yielding $31.4 \pm 10.54 \mathrm{~kg}$ of milk/d, with BCS of $3.0 \pm 0.45$, lactation number of $2.4 \pm 1.41$, and AI number of 3.3 \pm 3.62 . Cows were housed in a compost-bedded pack barn with free access to water and mineral salt and fed ad libitum with a TMR diet based on corn silage as forage, concentrate based on corn and soybean meal, and minerals and vitamins balanced to meet or exceed the nutritional requirements of lactating dairy cows (NRC, 2001).

Throughout the experiment, cows in both farms were milked 3 times daily, $8 \mathrm{~h}$ apart, and all received 500 mg of recombinant bST (Lactotropin; Elanco Saúde Animal, São Paulo, Brazil) every 14 d, starting at approximately $60 \mathrm{~d}$ postpartum.

\section{Protocols and Treatments}

Cows were randomly assigned to 1 of 2 treatment groups using a completely randomized design of treatments. At the beginning of the FTAI protocol $(\mathrm{d}-10)$, the cows received an autoclaved (AUT; $\mathrm{n}=177$ ) or chemically disinfected (CHEM; $\mathrm{n}=172$ ) 8-d used intravaginal P4 implant (CIDR, Zoetis, São Paulo, Brazil; $1.9 \mathrm{~g}$ of P4) that remained for $8 \mathrm{~d}$. Immediately after P4 insertion, cows were treated with EB (Gonadiol, MSD Saúde Animal, São Paulo, Brazil; $2.0 \mathrm{mg}$ of EB i.m.) and GnRH (Fertagyl, MSD Saúde Animal, $100 \mu \mathrm{g}$ of gonadorelin i.m.). At $7(\mathrm{~d}-3)$ and $8(\mathrm{~d}-2)$ $\mathrm{d}$ after implant insertion, $\mathrm{PGF}_{2 \alpha}$ (Lutalyse, Zoetis, 25 mg of dinoprost tromethamine i.m.) was administered, and on $\mathrm{d}-2$, after withdrawal of the $\mathrm{P} 4$ implant, cows received EC (ECP, Zoetis; $1.0 \mathrm{mg}$ of EC i.m.) to synchronize ovulation. Fixed-time AI was performed at d 0, $48 \mathrm{~h}$ after EC administration, and cows were bred with conventional frozen/thawed semen from Holstein sires (Figure 1).

After treatments on $\mathrm{d}-2$, a subset of 115 cows from farm A received a heat detection device (Estrotect, IVP Brasil, São Paulo, Brazil), which remained until d 0, the time of AI. Cows that had greater than half of the patch coating removed were classified as exhibiting standing estrus.

\section{BCS, DIM, Milk Yield, and Ovarian Structures}

At experiment enrollment, all cows were scored for body condition using a 1 to 5 scale (Ferguson et al., 1994). For this experiment, BCS was categorized as lower BCS $(<2.75)$ or higher BCS $(\geq 2.75)$ and also categorized by DIM into lower $(<120)$ or higher $(\geq 120)$ days after calving. Based on parity, milk yield was categorized for primiparous cows into lower $(\leq 27.6 \mathrm{~kg}$ of milk/d) or higher ( $>27.6 \mathrm{~kg}$ of milk/d) and multiparous cows into lower $(\leq 31.9 \mathrm{~kg}$ of milk/d) or higher $(>31.9$ $\mathrm{kg}$ of milk/d) for further analyses.

From the majority of the cows $(n=142)$ on farm A, ovaries were evaluated using a transrectal ultrasound machine (DP-2200 VET; Mindray, Shenzhen, China) with a $7.5-\mathrm{MHz}$ linear-array transducer on $\mathrm{d}-10,-8$, $-6,-3,-2$, and 0 of the protocol and on d 5 after FTAI. At the beginning of the experiment $(\mathrm{d}-10)$, ovaries were evaluated to confirm the presence or absence of a CL and to measure the diameter of the largest follicle. Ovaries were again evaluated on $\mathrm{d}-3$ to confirm the presence or absence of CL and to determine whether CL regression occurred between $\mathrm{d}-10$ and -3 . Ovulation following the treatments on $\mathrm{d}-10$ was recorded on $d-8$ by the disappearance of any ovulatory follicle and it was confirmed on $\mathrm{d}-6$ by the presence of a new CL. Further evaluations were performed to determine the day of follicle wave emergence and to characterize the future ovulatory follicle growth and size until d 0. The size of the follicles and CL was based on the average cross-sectional diameter. On d 5, ovulation and number of ovulations were confirmed by detection of a 


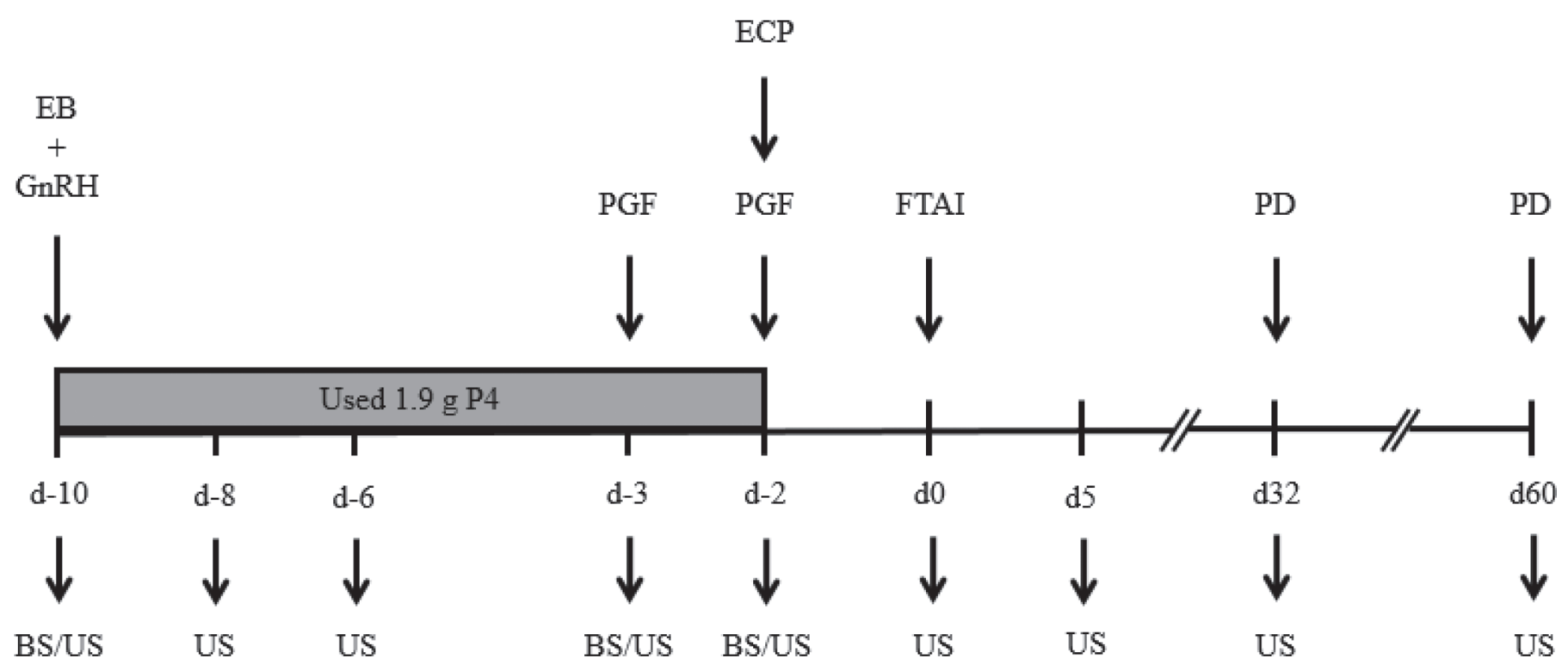

Figure 1. Diagram of activities. Cows were submitted to a fixed-time artificial insemination (FTAI) protocol, in which on $\mathrm{d}-10$ they were randomized to receive either a reused autoclaved (AUT) or chemically disinfected (CHEM) intravaginal progesterone (P4) implant (1.9 g), followed by an intramuscular treatment with $2.0 \mathrm{mg}$ of estradiol benzoate $(\mathrm{EB})$ and $100.0 \mu \mathrm{g}$ of gonadorelin $(\mathrm{GnRH})$. On d -3 and $-2,25.0 \mathrm{mg}$ of dinoprost tromethamine (PGF) was administered i.m. Also on $\mathrm{d}-2$, the P4 implants were removed and cows received 1.0 mg of estradiol cypionate (ECP) i.m. All cows were inseminated on d 0. By ultrasonography, ovulation was confirmed on d 5 and pregnancy diagnosis (PD) was performed on d 32 and confirmed on d 60 . US = ovary evaluated using ultrasound; BS = blood sample for serum P4 concentration.

CL ipsilateral to the ovary in which ovulatory follicles were present.

\section{Intravaginal P4 Implants Preparation}

The autoclaved and chemically disinfected implants were previously used in lactating dairy cows for $8 \mathrm{~d}$. After removal, the implants were washed in clean running water and air-dried at room temperature. Prior to use in the experiment, the implants were autoclaved or chemically disinfected. The protocol used to autoclave the P4 implants was similar to the one described by Cerri et al. (2009). Briefly, the inserts were placed in autoclave bags and autoclaved for $15 \mathrm{~min}$ at $121^{\circ} \mathrm{C}$ and $725 \mathrm{mmHg}$. For chemical disinfection, the implants were dipped for $15 \mathrm{~min}$ in 1:2,000 diluted quaternary ammonia (CB-30 TA; Ourofino, São Paulo, Brazil) and air-dried at room temperature.

\section{Blood Collection and P4 Assay}

From most of the cows $(\mathrm{n}=142)$ on farm A, blood samples for $\mathrm{P} 4$ measurements were collected by puncture of the coccygeal vein or artery into $10-\mathrm{mL}$ evacuated tubes (Vacutainer; Becton Dickinson, Franklin Lakes, NJ) immediately before administration of treatments on $\mathrm{d}-10,-3$, and -2 . After collection, samples were placed in ice and transported to the laboratory within $5 \mathrm{~h}$ and kept refrigerated overnight. Blood tubes were centrifuged at $1,900 \times g$ for $15 \mathrm{~min}$ at $4^{\circ} \mathrm{C}$ and serum was frozen at $-20^{\circ} \mathrm{C}$ for further analyses of $\mathrm{P} 4$ by a solid-phase RIA using a commercial kit (ImmuChem Progesterone CT, 07-270105, MP Biomedicals, Santa Ana, CA), according to the manufacturer's instruction, except for incubation. Briefly, after bringing standards from the kit, samples, coated tubes, and progesterone I125 to room temperature, $100 \mu \mathrm{L}$ of samples and standards were pipetted to the tubes. When all samples have been pipetted, $1.0 \mathrm{~mL}$ of progesterone I125 was added to all tubes and vortexed briefly. Tubes were incubated overnight at room temperature (instead of in a water bath at $37^{\circ} \mathrm{C}$ for $2 \mathrm{~h}$ ) and then aspirated and counted in a gamma counter. The assay sensitivity was $0.02 \mathrm{ng} / \mathrm{mL}$ and the intra-assay coefficient of variation was $6.9 \%$.

\section{Pregnancy Diagnosis and Reenrollment of Previously Synchronized Cows}

Pregnancy diagnosis was determined at $32 \mathrm{~d}$ after AI by transrectal ultrasonography (DP-2200 VET; Mindray) of the reproductive tract. Pregnant cows were reconfirmed at $60 \mathrm{~d}$ after AI. At each pregnancy diagnoses, pregnancy was only designated if the embryo was identified and had heartbeat. Pregnancy per AI was calculated at d 32 and 60, and pregnancy loss was recorded between these 2 evaluations. Cows that were diagnosed not pregnant at any time during the experi- 
ment were reenrolled in the experiment for further resynchronization.

\section{Statistical Analysis}

Categorical data were analyzed by logistic regression using the GLIMMIX procedure of SAS version 9.4 (SAS/STAT, SAS Institute Inc., Cary, NC) fitting a binary distribution response. The models included the fixed effects of treatment on $\mathrm{d}-10$, parity (primiparous and multiparous), categorized milk yield within parity (below or above the mean value), categorized DIM (below or above 120 DIM), categorized BCS (low or moderate), as well as the interactions between treatments and parity, treatments and categorized milk yield, treatments and categorized DIM, and treatments and categorized BCS. The estimates were back-transformed using the ILINK function of SAS to generate the adjusted Tukey percentages, and the results are expressed as least squares means \pm standard error of means. The Kenward-Roger method was used to calculate the denominator degrees of freedom to approximate the $F$ tests in the mixed models. Model fitting was evaluated using the fit statistics.

The continuous data, such as size of the largest follicle on $d-10$, size of the largest follicle on $d-6$, size of the largest follicle on $\mathrm{d}-3$, size of the largest follicle on $\mathrm{d}-2$, size of the largest follicle on $\mathrm{d} 0$, and serum $\mathrm{P} 4$ concentrations on $\mathrm{d}-10, \mathrm{~d}-3$ and $\mathrm{d}-2$, were analyzed using the MIXED procedure of SAS version 9.4. Data were tested for normality of residuals using the UNIVARIATE procedure of SAS. The P4 data were analyzed as nonparametric using the KruskalWallis test ordered by the RANK procedure of SAS. The models included the fixed effects of treatment on d -10 , parity, categorized milk yield, categorized DIM, categorized BCS, farm, and the interactions between treatments and parity, treatments and categorized milk yield, treatments and categorized DIM, treatments and categorized BCS, and treatments and farm. The Kenward-Roger method was used to calculate the denominator degrees of freedom to approximate the $F$-tests in the mixed models. The estimates were backtransformed using the PDIFF function of SAS to generate the adjusted Tukey comparisons of means.

When a treatment outcome was 0 or $100 \%$, we used the Fisher Exact Test using the FREQ procedure of SAS. The results are expressed as least squares means \pm standard error of the means. For all analyses, only variables with $P<0.20$ were kept in the final model, unless the variable was essential, such as treatments and their interactions. Differences were considered significant when $P \leq 0.05$, whereas a tendency was defined as $0.10 \geq P>0.05$.

\section{RESULTS AND DISCUSSION}

This experiment was performed with reused $1.9 \mathrm{~g}$ intravaginal P4 implants (previously used for $8 \mathrm{~d}$ in lactating dairy cows) that were either autoclaved or chemically disinfected before reuse, based on the differences in circulating $\mathrm{P} 4$ profiles that were obtained from a previous study from our laboratory (Melo et al., 2018). Cerri et al. (2009) compared a new and reused-after-autoclaving 1.38-g P4 implant in a GnRHbased protocol, but no previous comparison has been made between P4 implants prepared by the 2 different disinfection/sanitization techniques that produced such dramatic differences in circulating $\mathrm{P} 4$ profiles. In addition, although the combination of $\mathrm{GnRH}$ and $\mathrm{EB}$ at the beginning of the protocol has been investigated before in an E2/P4-based FTAI protocol (Pereira et al., 2015), the follicular dynamics and the effects of used implants in FTAI protocol, prepared by autoclaving versus chemical disinfection, had not been previously reported.

In beef cattle, especially in Bos indicus cows, chemically disinfected implants with different days of use have been compared with new implants (Crepaldi et al., 2009; Sales et al., 2009), with similar results in P/ AI. In dairy cattle, Cerri et al. (2009) did not detect differences in fertility when reused, autoclaved implants were compared with new 1.38 -g P4 implants. In our study, P4 concentrations were not affected by treatments on $\mathrm{d}-10$ (before any treatment) or -3 (Table 1). Based on P4 profiles of 1.9-g intravaginal implants from a previous study (Melo et al., 2018) it was expected that cows that received an autoclaved P4 implant would have greater circulating $\mathrm{P} 4$ throughout the protocol, particularly during the first $4 \mathrm{~d}$. Unexpectedly, P4 concentrations were slightly but significantly $(P=0.05)$ greater on $\mathrm{d}-2$ in cows with chemically disinfected rather than autoclaved P4 implants. Possibly, this unexpected difference could be due to a less effective induction of luteolysis in cows receiving chemically disinfected P4 implants. This could be related to the previous observation that CL did not completely regress after $1 \mathrm{PGF}_{2 \alpha}$ treatment in a relatively high percentage of cows, resulting in reduced fertility (Souza et al., 2007; Brusveen et al., 2009; Pereira et al., 2013b; Monteiro et al., 2015). Beyond that, this greater circulating $\mathrm{P} 4$ on $\mathrm{d}-2$ observed in cows treated with chemically disinfected implants might have lowered LH pulse frequency and, therefore, affected subsequent follicle or CL development or function.

The size of the largest follicle did not differ on $\mathrm{d}$ -10 , before treatment, but we noted a significant effect of presence of a CL and an interaction of presence of CL and type of implant on follicle size on $\mathrm{d}-3$ and 
PROGESTERONE-BASED FIXED-TIME ARTIFICIAL INSEMINATION

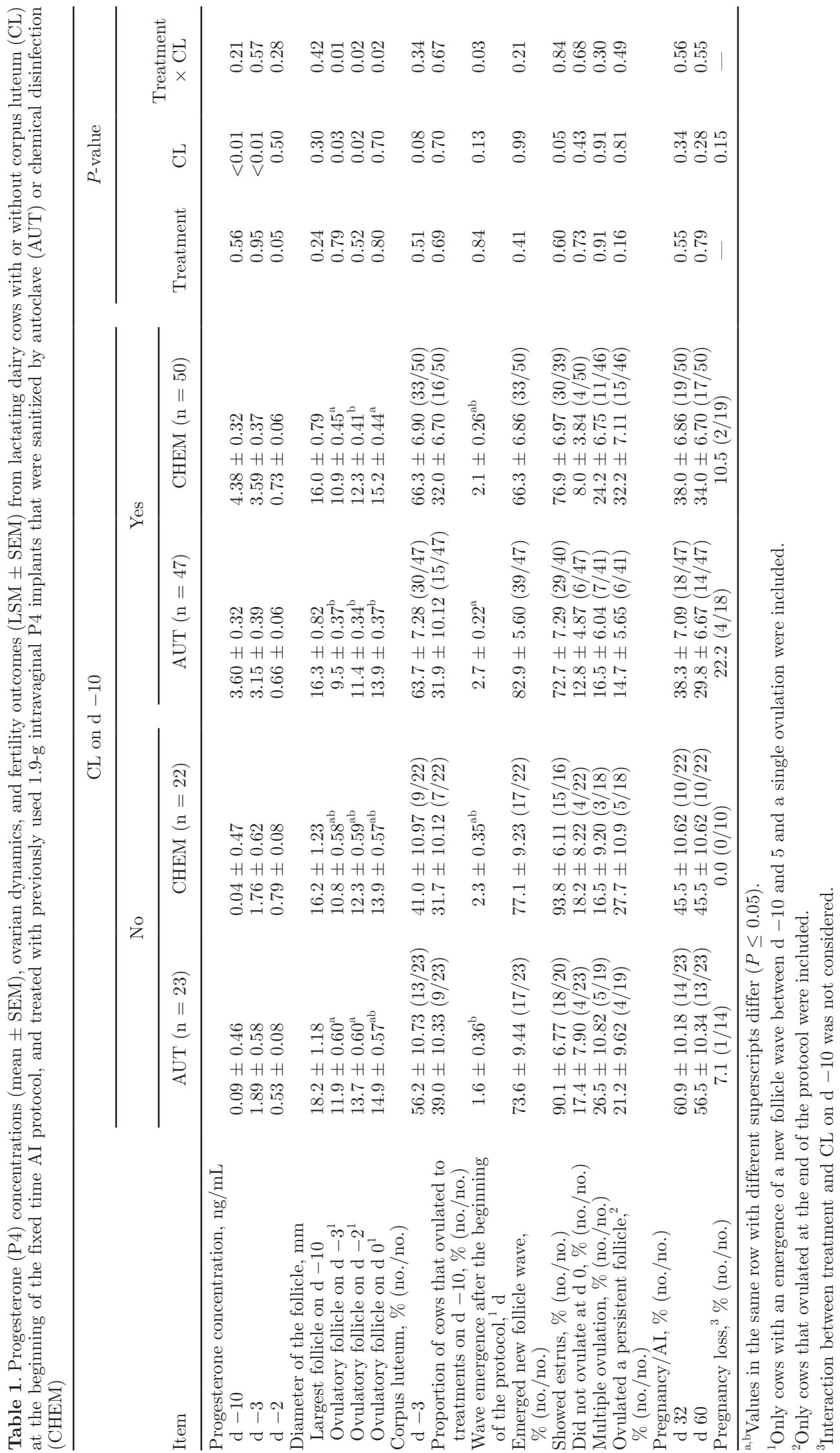


-2 (Table 1). Thus, cows with a CL at the start of the protocol had a smaller subsequent ovulatory follicle than cows without a CL, and follicle size was further reduced by the use of the autoclaved $\mathrm{P} 4$ implant rather than the chemically disinfected implant. However, we found no effect of presence of CL at the start of the protocol on ovulatory follicle size $(P=0.70)$, but the interaction between type of $\mathrm{P} 4$ implant sanitization and presence of CL was still observed $(P=0.02)$, with the smallest ovulatory follicle found in cows with a CL at the start of the protocol and treated with the autoclaved P4 (Table 1). It seems likely that the presence of a CL combined with the greater release of $\mathrm{P} 4$ from an autoclaved P4 implant produced greater circulating P4 concentrations that could affect ovulatory follicle growth due to a reduction in LH pulse frequency (Adams et al., 1992; Bergfeld et al., 1995, 1996).

Alternatively, cows that did not have a CL at the beginning of the protocol and received an autoclaved P4 implant had earlier $(P=0.03)$ wave emergence after treatments on $\mathrm{d}-10$, and subsequently had a larger $(P$ $=0.02$ ) ovulatory follicle diameter on $\mathrm{d}-2$ compared with cows that had a CL and received either type of P4 implant. However, the ovulatory follicle diameter on $\mathrm{d}$ 0 was not different (Table 1 ).

Nevertheless, we observed no effect of type of P4 implant treatment on the percentage of cows that ovulated to the $\mathrm{GnRH}$ at the beginning of the protocol $(33.1 \%)$ or percentage of cows with a CL at the time of $\mathrm{PGF}_{2 \alpha}$ treatment $(\mathrm{d}-3)$, although there tended to be a greater proportion of cows with a CL on $\mathrm{d}-3$ when a CL was initially present on $\mathrm{d}-10$, as would be expected (Table 1). If GnRH is given at the beginning of the protocol, it may induce ovulation in cows with a follicle greater than $10 \mathrm{~mm}$, causing formation of a new CL with the expected increase in $\mathrm{P} 4$ concentrations at the time of $\mathrm{PGF}_{2 \alpha}$ treatment (Souza et al., 2008). When GnRH was given at the beginning of the E2/P4based protocol, a greater proportion of cows had CL at the time of $\mathrm{PGF}_{2 \alpha}$ treatment, with elevated circulating $\mathrm{P} 4$ concentrations and greater fertility (Pereira et al., 2015). Although we were not able to detect difference in $\mathrm{P} / \mathrm{AI}$ between cows having (YES) or not having (NO) $\mathrm{CL}$ at $\mathrm{d}-10$ (Table 1 ) or -3 (data not shown), the expected elevation in $\mathrm{P} 4$ concentrations (either with a $\mathrm{CL}$ or greater $\mathrm{P} 4$ release from an implant) during preovulatory follicle development should provide a better endocrine environment for oocyte maturation, potentially leading to improved fertility (Cerri et al., 2011b; Binelli et al., 2014). Nevertheless, the lack of treatment difference in $\mathrm{P} / \mathrm{AI}$ for cows with or without a CL may indicate that the increased $\mathrm{P} 4$ from the autoclaved implant may be insufficient to produce physiologically significant changes in circulating $\mathrm{P} 4$ in cows either with or without a CL. Use of a single new CIDR or autoclaved, reused CIDR did not produce luteal phase concentrations of circulating P4 in high-producing lactating dairy cows without a CL, as they were initially developed for nonparous dairy heifers $(300-400 \mathrm{~kg}$ of BW) in New Zealand (Macmillan et al., 1991; Melo et al., 2018). High-producing dairy cows without a CL require 2 of these implants to achieve sufficient circulating P4 to optimize fertility (Padula and Macmillan, 2006; Bisinotto et al., 2013; Pereira et al., 2017.

Although no differences were observed in the proportion of cows ovulating at the beginning of the protocol, the earlier wave emergence observed in the AUT group from cows not bearing a CL may be explained by $\sim 18 \%$ more cows ovulating in this group on $\mathrm{d}-10$ (Table 1 ). It is not possible to define whether cows ovulated to GnRH or EB; however, based on previous data (Melo et al., 2016), several cows in a random phase of the estrous cycle ovulated when EB was used at the beginning of the protocol, in spite of the presence of an intravaginal $\mathrm{P} 4$ implant, and $\sim 34 \%$ ovulated when $\mathrm{GnRH}$ was used also in the presence of a $\mathrm{P} 4$ insert. Based on our results, the combination of $\mathrm{GnRH}$ and $\mathrm{EB}$ at the start of the protocol does not seem to have increased ovulation rate. When cows ovulate in a normal estrous cycle, a new follicular wave starts on the same day of the GnRH-induced gonadotropin surge (Sartori et al., 2004). However, even with an earlier emergence of a new follicular wave $(P=0.03$; Figure $2 \mathrm{~A})$, it is likely that cows ovulating at the beginning of the protocol in our study had delayed wave emergence because of the negative feedback on FSH induced by the high circulating E2 that originated from the EB treatment (Sartori et al., 2016). On the other hand, most of the nonovulating cows had later follicle wave emergence, $\sim 3 \mathrm{~d}$ after the start of the protocol $(P=0.01$; Figure $2 \mathrm{~A})$, which might explain the delay in the day of wave emergence in cows bearing a CL on $d-10$ from the AUT group, with more cows probably synchronized to EB (Table 1 and Figure 2A). This finding is in agreement with other authors that showed the expected follicle wave emergence starting at 3 to $5 \mathrm{~d}$ after $\mathrm{EB}$ treatments (Bó et al., 1995; Sartori et al., 2003; Souza et al., 2009; Monteiro et al., 2015). Furthermore, less than $40 \%$ of cows ovulated to treatments at the beginning of the protocol, which was unexpectedly low compared with some previous studies that reported $\sim 50 \%$ ovulation at the start of GnRH-based protocols that were initiated on a random day of the estrous cycle (Giordano et al., 2012b; Bilby et al., 2013; Bisinotto et al., 2013; Lopes et al., 2013), although the low ovulatory response is in agreement with other authors (Monteiro et al., 2015; Melo et al., 2016). It seems possible that this dose of GnRH (100 $\mu \mathrm{g}$ of gonadorelin) may not elicit a suffi- 

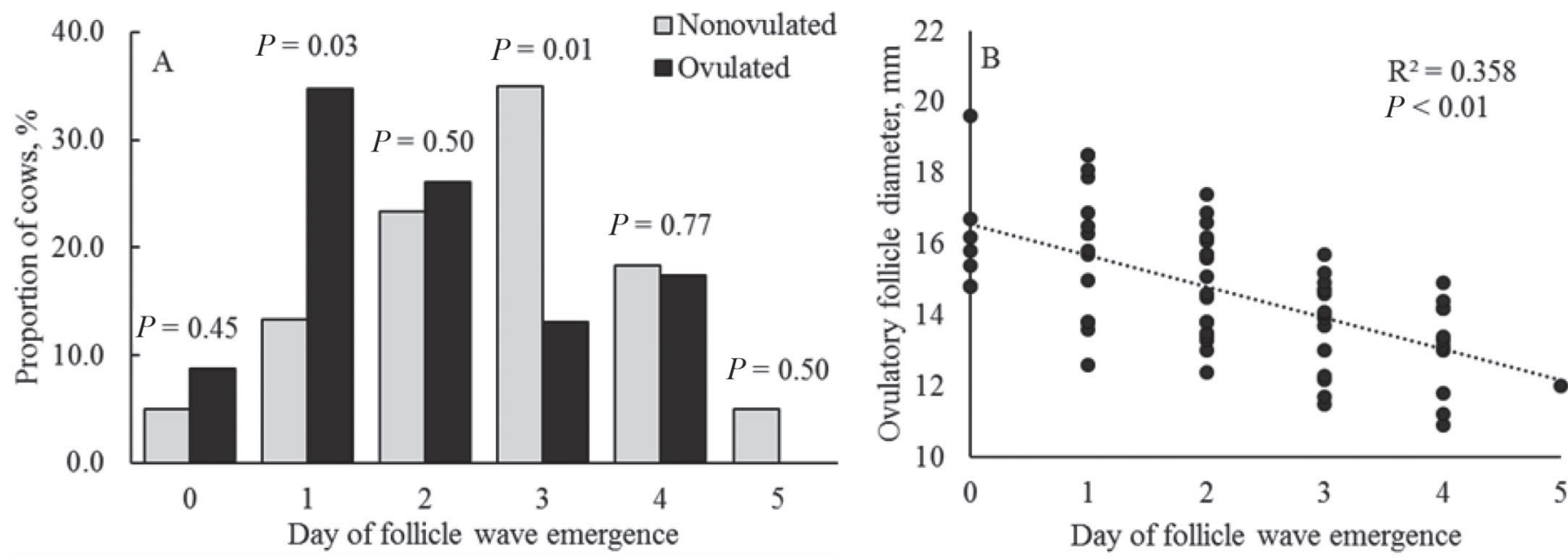

Figure 2. (A) Proportion of cows that ovulated (46/47) or not (60/95) at the beginning of the protocol and emerged a new follicular wave in relation to the day of follicle wave emergence. (B) Relationship between ovulatory follicle diameter and the day of follicle wave emergence in lactating dairy cows $(\mathrm{n}=52)$.

cient LH surge. Previous research has shown differences between GnRH products in ovulation efficacy (Martínez et al., 2003, Souza et al., 2009) and that a higher dose of $\mathrm{GnRH}(200 \mu \mathrm{g})$ can dramatically increase the magnitude of the LH surge, which may be particularly important in cows with greater $\mathrm{P} 4$ concentrations (Souza et al., 2009; Giordano et al., 2012a).

Independent of treatments or the presence of the CL on $d-10$, ovulating cows at the beginning of the protocol had follicle wave emergence $0.7 \mathrm{~d}$ earlier than nonovulating cows $(P<0.02)$, even in the presence of high circulating EB-induced E2 (Table 2). As mentioned, suppressed circulating FSH is expected when heifers or cows are treated with the combination of $\mathrm{P} 4$ /progestins and EB (O'Rourke et al., 2000; Sartori et al., 2003; Martínez et al., 2005). However, Ramos et al. (2010) submitted crossbred heifers to ovum pick-up (OPU) sessions and treated them with $\mathrm{P} 4 /$ progestins at the time of OPU, but only reported a marginal suppression in FSH concentrations in response to treatment with EB; therefore, delayed emergence of a new follicle wave did not occur when EB was given immediately after OPU. Similarly, in our study, if cows ovulated at the beginning of the protocol, EB combined with $\mathrm{P} 4$ probably did not efficiently suppress FSH, and, therefore, emergence of a new follicular wave was earlier than expected.

Although we found no difference in the proportion of cows with CL at the start of the protocol between cows that ovulated (Yes) or did not ovulate (No) at the beginning of the protocol $(\sim 70 \%$; $P=0.71)$, cows that ovulated at the beginning tended $(P=0.10)$ to have lower $\mathrm{P} 4$ concentrations on $\mathrm{d}-10$ compared with nonovulating cows (Table 2). Increased ovulation rate in cows with lower circulating $\mathrm{P} 4$ was expected due to the increased magnitude of the GnRH-induced $\mathrm{LH}$ surge (Colazo et al., 2008; Dias et al., 2010; Giordano et al., 2012a). Moreover, greater P4 can affect LH receptor expression in granulosa cells (Dias et al., 2014) and may initiate atresia of a dominant follicle (Adams et al., 1992).

Independent of treatments, a greater $(P<0.01)$ proportion of ovulating cows at the beginning of the protocol had CL and greater $(P<0.01)$ circulating $\mathrm{P} 4$ on $\mathrm{d}-3$ and -2 compared with nonovulating cows (Table 2). During the FTAI protocol, $2 \mathrm{PGF}_{2 \alpha}$ treatments were performed on $d-3$ and -2 . Because most of the ovulating cows had a new CL or $>1$ CL on $d$ -3 , it is likely that $24 \mathrm{~h}$ after the first treatment with $\mathrm{PGF}_{2 \alpha}$ was insufficient to detect complete regression of the CL and basal circulating P4 (Souza et al., 2007; Brusveen et al., 2009; Pereira et al., 2013b).

The treatments did not affect $(P=0.41)$ the percentage of cows emerging a new follicular wave at the beginning of the protocol. On average, $74.7 \%$ of the cows emerged a new follicular wave (Table 1 and Table 3 ); however, when cows ovulated after the start of the protocol, a greater $(P<0.01)$ proportion of cows emerged a new follicular wave compared with cows not ovulating (Table 2). Similar results were described in a previous study that reported that $73.8 \%$ of cows had emergence of a new follicular wave in an E2/P4-based protocol (Monteiro et al., 2015). Surprisingly, $25 \%$ of the cows in our study did not have synchronized emergence of a new follicular wave, even when EB was combined with GnRH at the start of the protocol, and these cows subsequently ovulated a persistent follicle at the end of the protocol (Table 1 and Table 3). Fertility 
Table 2. Progesterone (P4) concentrations (mean \pm SEM), ovarian dynamics, and fertility outcomes (LSM \pm SEM) from lactating dairy cows that ovulated (Yes) or did not ovulate (No) at the beginning of the fixed time AI protocol, independent of treatments with an autoclaved or chemically disinfected reused 1.9-g intravaginal P4 implant

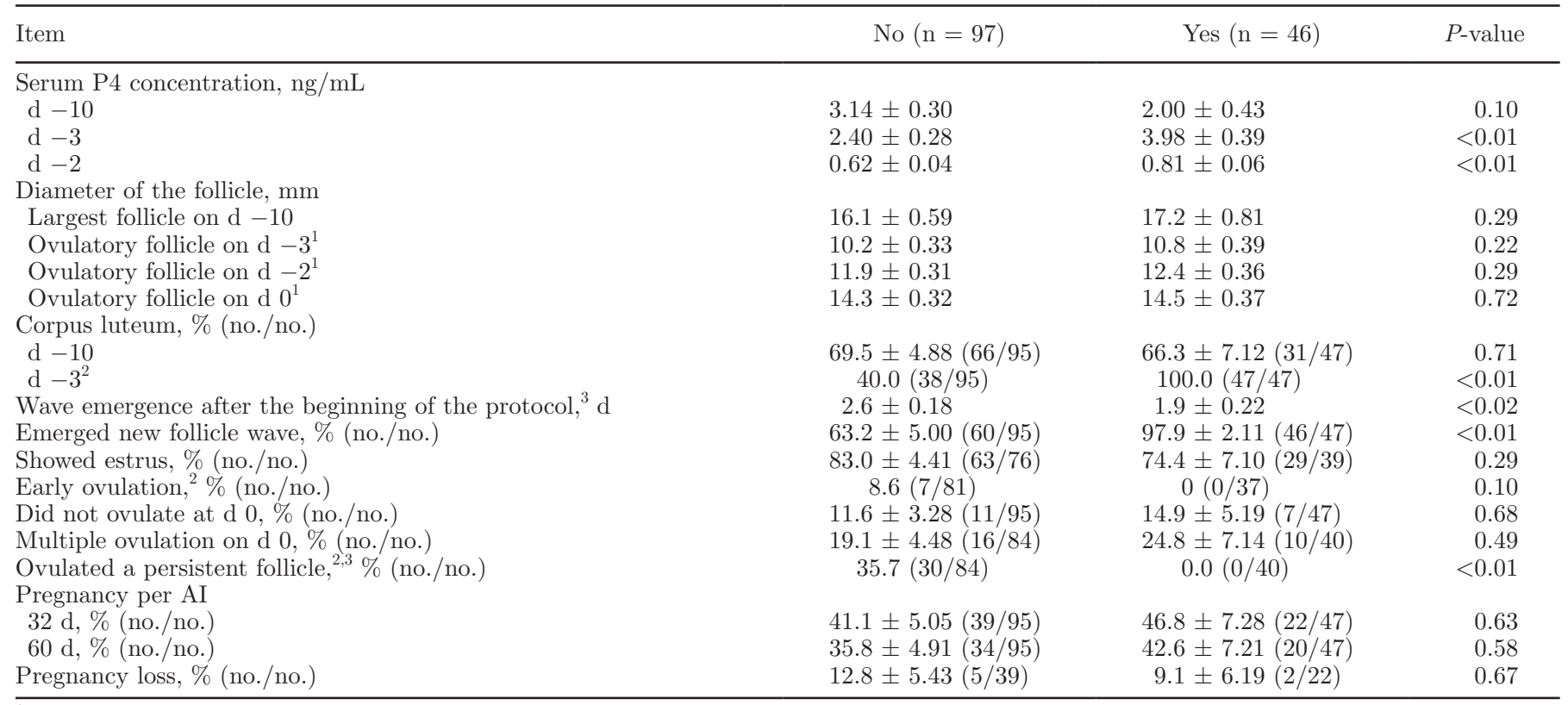

${ }^{1}$ Only cows with emergence of a new follicle wave between $\mathrm{d}-10$ and -5 and a single ovulation were included.

${ }^{2}$ Data were analyzed by the Fisher Exact Test.

${ }^{3}$ Only cows with emergence of a new follicle wave between $\mathrm{d}-10$ and -5 .

is compromised when cows ovulate a persistent follicle at the end of the FTAI protocol, with 51\% more pregnancies in cows that had emergence of a new follicular wave compared with cows ovulating a persistent follicle (Monteiro et al., 2015). In our study, 33\% more cows became pregnant when a new follicle wave emerged, although this did not reach statistical significance.

In addition to the problem with lack of emergence of a new follicular wave, $12.7 \%$ of cows failed to ovulate to the EC treatment at the end of the protocol. Likewise, other studies using E2/P4-based FTAI protocols have also shown similar or even greater rates of ovulation failure (Pereira et al., 2013b; Monteiro et al., 2015). Distinct pharmacodynamic differences exist between E2-esters, such as EB and EC (Souza et al., 2005), often used to induce ovulation at the end of E2/P4-based protocols (Pereira et al., 2013a, 2015; Melo et al., 2016). After treatment of cows with the same dosage of EB, compared with EC, EB treatment produced an earlier increase (16.0 vs. $30.7 \mathrm{~h})$ and a greater maximum E2 peak (9.6 vs. $3.4 \mathrm{pg} / \mathrm{mL})$. This pattern of E2 increase could produce a more synchronized ovulation. On the other hand, EC treatment may provide a more prolonged elevation in circulating E2, which may provide a more

Table 3. Fertility outcomes from lactating dairy cows that were synchronized (Yes) or not synchronized (No), based on emergence of a new follicular wave or ovulation at the end of the fixed time AI protocol

\begin{tabular}{|c|c|c|c|c|}
\hline Item & $\begin{array}{c}\text { Cows with response, }{ }^{1} \% \\
\text { (no./no.) }\end{array}$ & \multicolumn{2}{|c|}{ Pregnancy per AI, \% (no./no.) } & $P$-value \\
\hline $\begin{array}{l}\text { Emerged new wave } \\
\text { Ovulated to protocol }^{3} \\
\text { Overall synchronization }^{4}\end{array}$ & $\begin{array}{l}74.6(106 / 142) \\
87.3(124 / 142) \\
66.2(94 / 142)\end{array}$ & $\begin{array}{l}41.5(44 / 106) \\
43.5(54 / 124) \\
46.8(44 / 94)\end{array}$ & $\begin{aligned} 27.8 & (10 / 36) \\
0.0 & (0 / 18) \\
20.8 & (10 / 48)\end{aligned}$ & $\begin{array}{r}0.15 \\
<0.01 \\
<0.01\end{array}$ \\
\hline
\end{tabular}

\footnotetext{
${ }^{1}$ Percentage of cows with the given response (emergence of a new follicle wave, ovulation at the end of the protocol, or overall synchronization to the fixed time AI protocol).

${ }^{2}$ Cows with emergence of a new follicle wave between $\mathrm{d}-10$ and -5 .

${ }^{3}$ Cows ovulating at the end of the protocol between $\mathrm{d}-0.5$ and 1.5 .

${ }^{4}$ Cows were considered synchronized to the fixed time AI protocol when they had new follicle wave emergence between $\mathrm{d}-10$ and -5 , and
} ovulation between $\mathrm{d}-0.5$ and 1.5 . 
physiological endocrine environment during proestrus (Souza et al., 2005; Binelli et al., 2014) and requires fewer management interventions. Other studies have shown that, despite these differences in circulating E2 profiles, ovulation rate did not differ between E2 esters and the expected time of the ovulation was also similar ( $\sim 72 \mathrm{~h}$ after intravaginal P4 implant removal; Baruselli et al., 2012). When EC was compared with GnRH at the end of the E2/P4 FTAI protocol, ovulation rate also did not differ between treatments (Ferreira et al., 2017). Furthermore, P/AI did not differ when EB and $\mathrm{EC}$ were compared at the end of the protocol (Melo et al., 2016). Thus, it seems likely that EC treatment is an efficient, but imperfect, method for inducing ovulation in this type of protocol. Several factors could compromise ovulation at the end of E2/P4-based protocols, such as insufficient circulating E2 concentrations from the combination of the EC treatment and the growing ovulatory follicle, which may produce a lack of $\mathrm{GnRH} /$ LH surge or an insufficient GnRH/LH surge to elicit ovulation (Sartori et al., 2001). Alternatively, small increases in $\mathrm{P} 4$ concentrations near the time of $\mathrm{AI}$, due to lack of complete CL regression, could inhibit the E2induced $\mathrm{GnRH} / \mathrm{LH}$ surge and thereby prevent ovulation (Souza et al., 2007; Brusveen et al., 2009; Bisinotto et al., 2010; Giordano et al., 2012a, 2013). We have shown that, in Holstein cows, ovulatory capacity was acquired when the follicle size was $>10 \mathrm{~mm}$ (Sartori et al., 2001); therefore, although the average size of the ovulatory follicle observed in this study was greater than $13 \mathrm{~mm}$ in all treatment groups, some cows in each group had smaller follicles at the end of the protocol. Moreover, small elevations in circulating $\mathrm{P} 4$ at the time of AI may compromise ovulation and fertility after EC treatment (Monteiro et al., 2015). Although we did not measure circulating $\mathrm{P} 4$ on the day of $\mathrm{AI}, \mathrm{P} 4$ concentrations were unexpectedly greater $(P=0.05)$ in cows from the CHEM group on $\mathrm{d}-2$, independent of the CL presence on $\mathrm{d}-10$ (Table 1$)$, and greater $(P<0.01)$ in cows ovulating to treatments on $\mathrm{d}-10$ (Table 2). It is likely that the threshold for P4 concentrations near AI is lower when EC is used as an ovulation inducer compared with GnRH, although the fertility threshold near the time of final GnRH treatment, to induce ovulation, was reported to be between 0.3 and $0.5 \mathrm{ng} / \mathrm{mL}$ (Souza et al., 2007; Brusveen et al., 2009; Giordano et al., 2012a). Thus, if complete luteolysis has not occurred by the time of AI, ovulation to EC might be compromised because of the inhibition of the EC-induced GnRH-LH surge, as the action of E2 at the hypothalamus can be blocked by P4 (Robinson et al., 2000; Richter et al., 2002).

In our study, overall synchronization was about $66.2 \%$ based on cows that emerged a new follicular wave and ovulated at the end of the protocol (Table 3). In another study, cows were considered synchronized when they did not have a CL on the day of AI, but had a CL 7 d later (>90\%; Pereira et al., 2014), which is very close to our finding that $87.3 \%$ of cows ovulated at the end of the protocol. Considering only ovulation to the protocol as the gold standard for synchronization seems to be inadequate, because cows that did not have emergence of a new follicular wave will ovulate a persistent follicle at the end of the protocol and should not be considered properly synchronized (Monteiro et al., 2015; Melo et al., 2016). Using both criteria for synchronization, synchronized cows had greater $(P<$ 0.01 ) fertility compared with cows not synchronized to the protocol (Table 3).

High multiple ovulations were observed in our study. Independent of treatments, presence of CL on $\mathrm{d}-10$, or ovulatory response to treatments on $\mathrm{d}-10, \sim 21 \%$ of the cows that ovulated at the end of the protocol had multiple ovulations (Table 1 and Table 2). Multiple ovulations are responsible for the high undesired twinning rate in high-producing lactating dairy cows (Wiltbank et al., 2006). Several risk factors are related to multiple ovulations and might account for the high multiple ovulations in our study, such as high milk production (Fricke and Wiltbank, 1999; Lopez et al., 2005) and low circulating P4 during preovulatory follicle growth (Wiltbank et al., 2012). The higher metabolism of steroid hormones underlies the reduced circulating P4 in lactating cows (Sangsritavong et al., 2002), but, interestingly, even cows that ovulated on $\mathrm{d}-10$, and therefore had greater $(P<0.01)$ circulating $\mathrm{P} 4$ concentrations on $\mathrm{d}-3$ compared with nonovulating cows, also had elevated multiple ovulation (24.8\%; Table 2). Although many risk factors may be involved in the occurrence of high multiple ovulations and twinning rate (Silvia del Rio et al., 2007), it is important to note that CL regression between $\mathrm{d}-10$ and -3 in our study was greater than $50 \%$ (data not shown), probably due to the use of EB at the initiation of the protocol (Monteiro et al., 2015; Melo et al., 2016). This phenomenon could underlie, at least in part, the high incidence of multiple ovulation observed in the present study.

Pregnancy per AI on d 32 and 60 or pregnancy loss were not affected by treatments, CL presence on $\mathrm{d}-10$, or ovulatory response to treatments at the beginning of the protocol (Table 1 and Table 2). Although we were not able to detect differences in fertility independent of treatments, a greater $(P=0.05)$ proportion of cows without a CL on $\mathrm{d}-10$ showed estrus at the end of the protocol, which could be related to the numerically greater $\mathrm{P} / \mathrm{AI}$ on d 32 and 60 and lower pregnancy loss (Table 1). Expression of estrus during an E2/P4-based FTAI protocol has been found to increase fertility and 
reduce pregnancy loss (Pancarci et al., 2002; Cerri et al., 2004; Galvão et al., 2004; Souza et al., 2007; Pereira et al., 2014, 2016). Displaying estrus at the end of an E2/P4-based protocol may be related to reduced P4 concentrations near $\mathrm{AI}$ and to increased E2 during proestrus due to E2 esters plus the endogenous E2 from the ovulatory follicle (Pereira et al., 2014). This prolonged exposure to E2 during proestrus may underlie the increased fertility and reduced pregnancy loss in cows displaying estrus, which can alter uterine gene and protein expression and provide a better environment for pregnancy maintenance (Binelli et al., 2014).

Finally, $\mathrm{P} / \mathrm{AI}$ was greater $(P=0.02)$ in farm A compared with farm $\mathrm{B}$, independent of treatments (Table 4). This may have been related to differences in management factors (such as cow-handling, overcrowding, and cow comfort; Schefers et al., 2010), nutritional factors (such as BCS; Carvalho et al., 2014), or disease challenges (Ribeiro et al., 2013).

\section{CONCLUSIONS}

The use of $\mathrm{P} 4$ implants that produce different profiles of circulating $\mathrm{P} 4$ during the FTAI protocol did not affect follicular dynamics, synchronization rate, or $\mathrm{P} /$ AI. Thus, either autoclaving or chemical disinfection of a reused CIDR produced similar results in the type of FTAI protocol used in this study. Obviously, a limitation for interpreting this research in field situations is that no comparison was done with reused P4 implants in other FTAI protocols and no comparison was done with new P4 implants. Nevertheless, physiologically, presence of CL at the beginning of the protocol or ovulation at the beginning of the FTAI protocol affected several reproductive variables, such as the timing and synchronization of follicular wave emergence, proportion of cows in estrus at the end of the protocol, and size of the ovulatory follicle. Beyond that, cows that were correctly synchronized during the protocol were more likely to become pregnant to the FTAI protocol.

\section{ACKNOWLEDGMENTS}

The authors thank the owners and staff of São Jorge Farm (São Pedro, SP, Brazil), and Santo Antônio Farm (Piracicaba, SP, Brazil) for the use of their cows and facilities. The first author (Leonardo F. Melo) was supported by a scholarship from the Coordination for the Improvement of Higher Education Personnel (CAPES) of Brazil. Co-authors were supported by scholarships from the National Council for Scientific and Technological Development $(\mathrm{CNPq})$ of Brazil and from the São Paulo Research Foundation (FAPESP). This project was funded by a grant from CNPq (\#460902/2014-8).

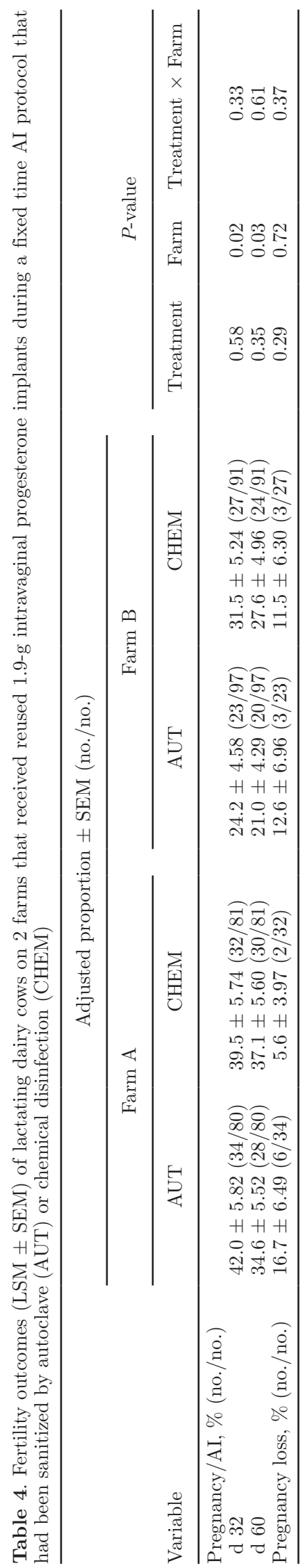




\section{REFERENCES}

Adams, G. P., R. L. Matteri, and O. J. Ginther. 1992. Effect of progesterone on ovarian follicles, emergence of follicular waves and circulating follicle-stimulating-hormone in heifers. J. Reprod. Fertil. 96:627-640.

Baruselli, P. S., M. F. Sa Filho, R. M. Ferreira, J. N. S. Sales, L. U. Gimenes, L. M. Vieira, M. F. Mendanha, and G. A. Bo. 2012. Manipulation of follicle development to ensure optimal oocyte quality and conception rates in cattle. Reprod. Domest. Anim. 47:134-141.

Bergfeld, E. G. M., F. N. Kojima, A. S. Cupp, M. E. Wehrman, K. E. Peters, V. Mariscal, T. Sanchez, and J. E. Kinder. 1996. Changing dose of progesterone results in sudden changes in frequency of luteinizing hormone pulses and secretion of $17 \beta$-Estradiol in bovine females. Biol. Reprod. 54:546-553.

Bergfeld, E. G., F. N. Kojima, M. E. Wehrman, A. S. Cupp, K. E. Peters, V. Mariscal, T. Sanches, R. J. Kittok, M. Garcia-Winder, and J. E. Kinder. 1995. Frequency of luteinizing hormone pulses and circulating $17 \beta$-oestradiol concentration in cows is related to concentration of progesterone in circulation when the progesterone comes from either an endogenous or exogenous source. Anim. Reprod. Sci. 37:257-265.

Bilby, T. R., R. G. S. Bruno, K. J. Lager, R. C. Chebel, J. G. N. Moraes, P. M. Fricke, G. Lopes Jr., J. O. Giordano, J. E. P. Santos, F. S. Lima, J. S. Stevenson, and S. L. Pulley. 2013. Supplemental progesterone and timing of resynchronization on pregnancy outcomes in lactating dairy cows. J. Dairy Sci. 96:7032-7042.

Binelli, M., R. Sartori, J. L. M. Vasconcelos, M. H. C. Pereira, P. L. J. Monteiro Jr., and R. S. Ramos. 2014. Evolution in fixed-time: From synchronization of ovulation to improved fertility. Pages 493-506 in Reproduction in Domestic Ruminants VIII. Vol. 1. 1st ed. J. L. Juengel, A. Miyamoto, C. Price, L. P. Reynolds, M. F. Smith, and R. Webb, ed. Context, Ashby de la Zouch, UK.

Bisinotto, R. S., E. S. Ribeiro, F. S. Lima, N. Martinez, L. F. Greco, L. Barbosa, P. P. Bueno, L. F. S. Scagion, W. W. Thatcher, and J. E. P. Santos. 2013. Targeted progesterone supplementation improves fertility in lactating dairy cows without a corpus luteum at the initiation of the timed artificial insemination protocol. J. Dairy Sci. 96:2214-2225.

Bisinotto, R. S., E. S. Ribeiro, L. T. Martins, R. S. Marsola, L. F. Greco, M. G. Favoreto, C. A. Risco, W. W. Thatcher, and J. E. P. Santos. 2010. Effect of interval between induction of ovulation and artificial insemination (AI) and supplemental progesterone for resynchronization on fertility of dairy cows subjected to a 5-d timed AI program. J. Dairy Sci. 93:5798-5808.

Bo, G. A., G. P. Adams, M. Caccia, M. Martinez, R. A. Pierson, and R. J. Mapletoft. 1995. Ovarian follicular wave emergence after treatment with progestogen and estradiol in cattle. Anim. Reprod. Sci. 39:193-204.

Bó, G. A., P. S. Baruselli, D. Moreno, L. Cutaia, M. Caccia, R. Tribulo, H. Tribulo, and R. J. Mapletoft. 2002. The control of follicular wave development for self-appointed embryo transfer programs in cattle. Theriogenology 57:53-72.

Brusveen, D. J., A. H. Souza, and M. C. Wiltbank. 2009. Effects of additional prostaglandin F-2 alpha and estradiol-17 beta during Ovsynch in lactating dairy cows. J. Dairy Sci. 92:1412-1422.

Burke, C. R., K. L. Macmillan, and M. P. Boland. 1996. Oestradiol potentiates a prolonged progesterone-induced suppression of LH release in ovariectomised cows. Anim. Reprod. Sci. 45:13-28.

Butler, W. R. 2000. Nutritional interactions with reproductive performance in dairy cattle. Anim. Reprod. Sci. 60-61:449-457.

Carvalho, P. D., A. H. Souza, M. C. Amundson, K. S. Hackbart, M. J. Fuenzalida, M. M. Herlihy, H. Ayres, A. R. Dresch, L. M. Vieira, J. N. Guenther, R. R. Grummer, P. M. Fricke, R. D. Shaver, and M. C. Wiltbank. 2014. Relationships between fertility and postpartum changes in body condition and body weight in lactating dairy cows. J. Dairy Sci. 97:3666-3683.

Cavalieri, J., G. Hepworth, K. I. Parker, P. J. Wright, and K. L. Macmillan. 2003. Effect of treatment with progesterone and oestradiol when starting treatment with an intravaginal progesterone releasing insert on ovarian follicular development and hormonal concentrations in Holstein cows. Anim. Reprod. Sci. 76:177-193.

Cerri, R. L. A., R. C. Chebel, F. Rivera, C. D. Narciso, R. A. Oliveira, M. Amstalden, G. M. Baez-Sandoval, L. J. Oliveira, W. W. Thatcher, and J. E. P. Santos. 2011a. Concentration of progesterone during the development of the ovulatory follicle: II. Ovarian and uterine responses. J. Dairy Sci. 94:3352-3365.

Cerri, R. L. A., R. C. Chebel, F. Rivera, C. D. Narciso, R. A. Oliveira, W. W. Thatcher, and J. E. P. Santos. 2011b. Concentration of progesterone during the development of the ovulatory follicle: I. Ovarian and embryonic responses. J. Dairy Sci. 94:3342-3351.

Cerri, R. L. A., H. M. Rutigliano, R. G. S. Bruno, and J. E. P. Santos. 2009. Progesterone concentration, follicular development and induction of cyclicity in dairy cows receiving intravaginal progesterone inserts. Anim. Reprod. Sci. 110:56-70.

Cerri, R. L. A., J. E. P. Santos, S. O. Juchem, K. N. Galvao, and R. C. Chebel. 2004. Timed artificial insemination with estradiol cypionate or insemination at estrus in high-producing dairy cows. J. Dairy Sci. 87:3704-3715.

Chebel, R. C., M. J. Al-Hassan, P. M. Fricke, J. E. P. Santos, J. R. Lima, C. A. Martel, J. S. Stevenson, R. Garcia, and R. L. Ax. 2010. Supplementation of progesterone via controlled internal drug release inserts during ovulation synchronization protocols in lactating dairy cows. J. Dairy Sci. 93:922-931.

Colazo, M. G., J. P. Kastelic, H. Davis, M. D. Rutledge, M. F. Martinez, J. A. Small, and R. J. Mapletoft. 2008. Effects of plasma progesterone concentrations on LH release and ovulation in beef cattle given GnRH. Domest. Anim. Endocrinol. 34:109-117.

Crepaldi, G. A., J. N. S. Sales, A. A. Teixeira, and P. S. Baruselli. 2009. Rate and time to ovulation in Nelore cows treated with estradiol cypionate or benzoate to induce ovulation on FTAI protocols. Anim. Reprod. 6:223.

Cunha, A. P., J. N. Guenther, M. J. Maroney, J. O. Giordano, A. B. Nascimento, S. Bas, H. Ayres, and M. C. Wiltbank. 2008. Effects of high vs. low progesterone concentrations during Ovsynch on double ovulation rate and pregnancies per AI in high producing dairy cows. J. Dairy Sci. 91(Suppl. 1):246. (Abstr.)

Dias, F. C. F., M. G. Colazo, J. P. Kastelic, R. J. Mapletoft, G. P. Adams, and J. Singh. 2010. Progesterone concentration, estradiol pretreatment, and dose of gonadotropin-releasing hormone affect gonadotropin-releasing hormone-mediated luteinizing hormone release in beef heifers. Domest. Anim. Endocrinol. 39:155-162.

Dias, H. P., J. P. Albuquerque, A. C. S. Castilho, and J. L. M. Vasconcelos. 2014. High progesterone concentration has a negative effect on the expression of LH receptors in granulosa cells from Nelore heifers. Pages 366-366 in Proc. 28th Annual Meeting of the Brazilian Embryo Technology Society (SBTE). Animal Reproduction, Natal, RN, Brazil.

Diskin, M. G., J. J. Murphy, and J. M. Sreenan. 2006. Embryo survival in dairy cows managed under pastoral conditions. Anim. Reprod. Sci. 96:297-311.

Ferguson, J. D., D. T. Galligan, and N. Thomsen. 1994. Principal descriptors of body condition score in Holstein cows. J. Dairy Sci. 77:2695-2703.

Ferreira, R. M., H. Ayres, L. U. Gimenes, F. P. Torres, F. A. Lima, M. B. Veras, T. G. Guida, R. V. Sala, and P. S. Baruselli. 2017. Inducing ovulation with oestradiol cypionate allows flexibility in the timing of insemination and removes the need for gonadotrophinreleasing hormone in timed AI protocols for dairy cows. Reprod. Fertil. Dev. 29:468-475.

Fricke, P. M., and M. C. Wiltbank. 1999. Effect of milk production on the incidence of double ovulation in dairy cows. Theriogenology 52:1133-1143.

Galvão, K. N., J. E. P. Santos, S. O. Juchem, R. L. A. Cerri, A. C. Coscioni, and M. Villasenor. 2004. Effect of addition of a progesterone intravaginal insert to a timed insemination protocol using estradiol cypionate on ovulation rate, pregnancy rate, and late embryonic loss in lactating dairy cows. J. Anim. Sci. 82:3508-3517.

Giordano, J. O., P. M. Fricke, J. N. Guenther, G. Lopes, M. M. Herlihy, A. B. Nascimento, and M. C. Wiltbank. 2012a. Effect of progesterone on magnitude of the luteinizing hormone surge induced 
by two different doses of gonadotropin-releasing hormone in lactating dairy cows. J. Dairy Sci. 95:3781-3793.

Giordano, J. O., M. C. Wiltbank, P. M. Fricke, S. Bas, R. Pawlisch, J. N. Guenther, and A. B. Nascimento. 2013. Effect of increasing GnRH and PGF(2 alpha) dose during Double-Ovsynch on ovulatory response, luteal regression, and fertility of lactating dairy cows. Theriogenology 80:773-783.

Giordano, J. O., M. C. Wiltbank, J. N. Guenther, R. Pawlisch, S. Bas, A. P. Cunha, and P. M. Fricke. 2012b. Increased fertility in lactating dairy cows resynchronized with Double-Ovsynch compared with Ovsynch initiated $32 \mathrm{~d}$ after timed artificial insemination. J. Dairy Sci. 95:639-653.

Inskeep, E. K. 2004. Preovulatory, postovulatory, and postmaternal recognition effects of concentrations of progesterone on embryonic survival in the cow. J. Anim. Sci. 82(E. Suppl.):24-39.

Lopes, G., J. O. Giordano, A. Valenza, M. M. Herlihy, J. N. Guenther, M. C. Wiltbank, and P. M. Fricke. 2013. Effect of timing of initiation of resynchronization and presynchronization with gonadotropin-releasing hormone on fertility of resynchronized inseminations in lactating dairy cows. J. Dairy Sci. 96:3788-3798.

Lopez, H., D. Z. Caraviello, L. D. Satter, P. M. Fricke, and M. C. Wiltbank. 2005. Relationship between level of milk production and multiple ovulations in lactating dairy cows. J. Dairy Sci. 88:27832793.

Lopez, H., L. D. Satter, and M. C. Wiltbank. 2004. Relationship between level of milk production and estrous behavior of lactating dairy cows. Anim. Reprod. Sci. 81:209-223.

Lucy, M. C. 2001. ADSA Foundation Scholar Award-Reproductive loss in high-producing dairy cattle: Where will it end? J. Dairy Sci. 84:1277-1293.

Macmillan, K. L., V. K. Taufa, D. R. Barnes, and A. M. Day. 1991. Plasma progesterone concentrations in heifers and cows treated with a new intravaginal device. Anim. Reprod. Sci. 26:25-40.

Martínez, M. F., J. P. Kastelic, G. A. Bo, M. Caccia, and R. J. Mapletoft. 2005. Effects of oestradiol and some of its esters on gonadotrophin release and ovarian follicular dynamics in CIDR-treated beef cattle. Anim. Reprod. Sci. 86:37-52.

Martínez, M. F., R. J. Mapletoft, J. P. Kastelic, and T. Carruthers. 2003. The effects of 3 gonadorelin products on luteinizing hormone release, ovulation, and follicular wave emergence in cattle. Can. Vet. J. 44:125-131.

Melo, L. F., P. L. J. Monteiro Jr., L. H. Oliveira, M. M. Guardieiro, J. N. Drum, M. C. Wiltbank, and R. Sartori. 2018. Circulating progesterone concentrations in nonlactating Holstein cows during reuse of intravaginal progesterone implants sanitized by autoclave or chemical disinfection. J. Dairy Sci. 101:3537-3544. https://doi .org/10.3168/jds.2017-13569.

Melo, L. F., P. L. J. Monteiro Jr., R. S. Surjus, J. N. Drum, M. C. Wiltbank, and R. Sartori. 2016. Progesterone-based fixed-time artificial insemination protocols for dairy cows: GnRH vs. estradiol benzoate at initiation and estradiol cypionate vs. estradiol benzoate at the end. J. Dairy Sci. 99:9227-9237.

Monteiro, P. L. J., Jr., M. Borsato, F. L. M. Silva, A. B. Prata, M. C. Wiltbank, and R. Sartori. 2015. Increasing estradiol benzoate, pretreatment with gonadotropin-releasing hormone, and impediments for successful estradiol-based fixed-time artificial insemination protocols in dairy cattle. J. Dairy Sci. 98:3826-3839.

Norman, H. D., J. R. Wright, S. M. Hubbard, R. H. Miller, and J. L. Hutchison. 2009. Reproductive status of Holstein and Jersey cows in the United States. J. Dairy Sci. 92:3517-3528.

NRC. 2001. Nutrient Requirements of Dairy Cattle. 7th rev. ed. Natl. Acad. Sci., Washington, DC.

O'Rourke, M., M. G. Diskin, J. M. Sreenan, and J. F. Roche. 2000. The effect of dose and route of oestradiol benzoate administration on plasma concentrations of oestradiol and FSH in long-term ovariectomised heifers. Anim. Reprod. Sci. 59:1-12.

Padula, A. M., and K. L. Macmillan. 2006. Effect of treatment with two intravaginal inserts on the uterine and vaginal microflora of early postpartum beef cows. Aust. Vet. J. 84:204-208.

Pancarci, S. M., E. R. Jordan, C. A. Risco, M. J. Schouten, F. L. Lopes, F. Moreira, and W. W. Thatcher. 2002. Use of estradiol cy- pionate in a presynchronized timed artificial insemination program for lactating dairy cattle. J. Dairy Sci. 85:122-131.

Pereira, M. H. C., A. D. P. Rodrigues, R. J. De Carvalho, M. C. Wiltbank, and J. L. M. Vasconcelos. 2014. Increasing length of an estradiol and progesterone timed artificial insemination protocol decreases pregnancy losses in lactating dairy cows. J. Dairy Sci. 97:1454-1464.

Pereira, M. H. C., A. D. P. Rodrigues, T. Martins, W. V. C. Oliveira, P. S. A. Silveira, M. C. Wiltbank, and J. L. M. Vasconcelos. 2013a. Timed artificial insemination programs during the summer in lactating dairy cows: Comparison of the 5-d Cosynch protocol with an estrogen/progesterone-based protocol. J. Dairy Sci. 96:6904-6914.

Pereira, M. H. C., C. P. Sanches, T. G. Guida, A. D. R. Rodrigues, F. L. Aragon, M. B. Veras, P. T. Borges, M. C. Wiltbank, and J. L. M. Vasconcelos. 2013b. Timing of prostaglandin F-2 alpha treatment in an estrogen-based protocol for timed artificial insemination or timed embryo transfer in lactating dairy cows. J. Dairy Sci 96:2837-2846.

Pereira, M. H. C., C. P. Sanches, T. G. Guida, M. C. Wiltbank, and J. L. M. Vasconcelos. 2017. Comparison of fertility following use of one versus two intravaginal progesterone inserts in dairy cows without a CL during a synchronization protocol before timed AI or timed embryo transfer. Theriogenology 89:72-78.

Pereira, M. H. C., M. C. Wiltbank, L. F. S. P. Barbosa, W. M. Costa Jr., M. A. P. Carvalho, and J. L. M. Vasconcelos. 2015. Effect of adding a gonadotropin-releasing-hormone treatment at the beginning and a second prostaglandin F-2 alpha treatment at the end of an estradiol-based protocol for timed artificial insemination in lactating dairy cows during cool or hot seasons of the year. J. Dairy Sci. 98:947-959.

Pereira, M. H. C., M. C. Wiltbank, and J. L. M. Vasconcelos. 2016 Expression of estrus improves fertility and decreases pregnancy losses in lactating dairy cows that receive artificial insemination or embryo transfer. J. Dairy Sci. 99:2237-2247.

Pursley, J. R., M. O. Mee, and M. C. Wiltbank. 1995. Synchronization of ovulation in dairy-cows using PGF(2-alpha), and GnRH. Theriogenology 44:915-923.

Ramos, A. F., R. Rumpf, J. U. Camara, M. R. Mollo, I. Pivato, A. P. Marques Jr., and R. Sartori. 2010. Effect of follicular wave synchronization on in vitro embryo production in heifers. Anim. Reprod. Sci. 117:201-207.

Revah, I., and W. R. Butler. 1996. Prolonged dominance of follicles and reduced viability of bovine oocytes. J. Reprod. Fertil. 106:3947.

Ribeiro, E. S., F. S. Lima, L. F. Greco, R. S. Bisinotto, A. P. A. Monteiro, M. Favoreto, H. Ayres, R. S. Marsola, N. Martinez, W. W. Thatcher, and J. E. P. Santos. 2013. Prevalence of periparturient diseases and effects on fertility of seasonally calving grazing dairy cows supplemented with concentrates. J. Dairy Sci. 96:5682-5697.

Richter, T. A., J. E. Robinson, and N. P. Evans. 2002. Progesterone blocks the estradiol-stimulated luteinizing hormone surge by disrupting activation in response to a stimulatory estradiol signal in the ewe. Biol. Reprod. 67:119-125.

Robinson, J. E., A. E. Healey, T. G. Harris, E. A. Messent, D. C. Skinner, J. A. Taylor, and N. P. Evans. 2000. The negative feedback action of progesterone on luteinizing hormone release is not associated with changes in GnRH mRNA expression in the ewe. J. Neuroendocrinol. 12:121-129.

Sales, J. N. S., G. A. Crepaldi, L. M. K. Dias, A. A. Teixeira, G. G. C. Cardoso, R. R. Grandinetti, V. G. Oliveira, I. M. Combi, and P. S. Baruselli. 2009. Evaluation of different protocols to induce cyclicity in prepubertal beef heifers. Anim. Reprod. 6:234.

Sangsritavong, S., D. K. Combs, R. Sartori, L. E. Armentano, and M. C. Wiltbank. 2002. High feed intake increases liver blood flow and metabolism of progesterone and estradiol-17 beta in dairy cattle. J. Dairy Sci. 85:2831-2842.

Santos, J. E. P., H. M. Rutigliano, and M. F. Sa Filho. 2009. Risk factors for resumption of postpartum estrous cycles and embryonic survival in lactating dairy cows. Anim. Reprod. Sci. 110:207-221. 
Sartori, R., P. M. Fricke, J. C. P. Ferreira, O. J. Ginther, and M. C. Wiltbank. 2001. Follicular deviation and acquisition of ovulatory capacity in bovine follicles. Biol. Reprod. 65:1403-1409.

Sartori, R., L. U. Gimenes, P. L. J. Monteiro, L. F. Melo, P. S. Baruselli, and M. R. Basto. 2016. Metabolic and endocrine differences between Bos taurus and Bos indicus females that impact the interaction of nutrition with reproduction. Theriogenology 86:32-40.

Sartori, R., J. M. Haughian, R. D. Shaver, G. J. M. Rosa, and M. C. Wiltbank. 2004. Comparison of ovarian function and circulating steroids in estrous cycles of Holstein heifers and lactating cows. J. Dairy Sci. 87:905-920.

Sartori, R., C. A. Suarez-Fernandez, R. L. Monson, J. N. Guenther, G. J. M. Rosa, and M. C. Wiltbank. 2003. Improvement in recovery of embryos/ova using a shallow uterine horn flushing technique in superovulated Holstein heifers. Theriogenology 60:1319-1330.

Savio, J. D., W. W. Thatcher, G. R. Morris, K. Entwistle, M. Drost, and M. R. Mattiacci. 1993. Effects of induction of low plasma progesterone concentrations with a progesterone-releasing intravaginal device on follicular turnover and fertility in cattle. J. Reprod. Fertil. 98:77-84.

Schefers, J. M., K. A. Weigel, C. L. Rawson, N. R. Zwald, and N. B. Cook. 2010. Management practices associated with conception rate and service rate of lactating Holstein cows in large, commercial dairy herds. J. Dairy Sci. 93:1459-1467.

Silvia del Rio, N., S. Stewart, P. Rapnicki, Y. M. Chang, and P. M. Fricke. 2007. An observational analysis of twin births, calf sex ratio, and calf mortality in Holstein dairy cattle. J. Dairy Sci. 90:1255-1264.

Souza, A. H., H. Ayres, R. M. Ferreira, and M. C. Wiltbank. 2008. A new presynchronization system (Double-Ovsynch) increases fertility at first postpartum timed AI in lactating dairy cows. Theriogenology 70:208-215.

Souza, A. H., A. P. Cunha, D. Z. Caraviello, and M. C. Wiltbank. 2005. Profiles of circulating estradiol-17 beta after different estrogen treatments in lactating dairy cows. Anim. Reprod. 2:224-232.

Souza, A. H., A. Gumen, E. P. B. Silva, A. P. Cunha, J. N. Guenther, C. M. Peto, D. Z. Caraviello, and M. C. Wiltbank. 2007. Supple- mentation with estradiol-17 beta before the last gonadotropinreleasing hormone injection of the ovsynch protocol in lactating dairy cows. J. Dairy Sci. 90:4623-4634.

Souza, A. H., S. Viechnieski, F. A. Lima, F. F. Silva, R. Araujo, G. A. Bo, M. C. Wiltbank, and P. S. Baruselli. 2009. Effects of equine chorionic gonadotropin and type of ovulatory stimulus in a timedAI protocol on reproductive responses in dairy cows. Theriogenology $72: 10-21$.

Stevenson, J. L., J. C. Dalton, J. E. P. Santos, R. Sartori, A. Ahmadzadeh, and R. C. Chebel. 2008. Effect of synchronization protocols on follicular development and estradiol and progesterone concentrations of dairy heifers. J. Dairy Sci. 91:3045-3056.

Stevenson, J. S., J. R. Pursley, H. A. Garverick, P. M. Fricke, D. J Kesler, J. S. Ottobre, and M. C. Wiltbank. 2006. Treatment of cycling and noncycling lactating dairy cows with progesterone during Ovsynch. J. Dairy Sci. 89:2567-2578.

Vishwanath, R. 2003. Artificial insemination: The state of the art. Theriogenology 59:571-584

Washburn, S. P., W. J. Silvia, C. H. Brown, B. T. McDaniel, and A. J. McAllister. 2002. Trends in reproductive performance in southeastern Holstein and Jersey DHI herds. J. Dairy Sci. 85:244-251.

Wiltbank, M., H. Lopez, R. Sartori, S. Sangsritavong, and A. Gumen. 2006. Changes in reproductive physiology of lactating dairy cows due to elevated steroid metabolism. Theriogenology 65:17-29.

Wiltbank, M. C., G. M. Baez, F. Cochrane, R. V. Barletta, C. R. Trayford, and R. T. Joseph. 2015. Effect of a second treatment with prostaglandin F-2 alpha during the Ovsynch protocol on luteolysis and pregnancy in dairy cows. J. Dairy Sci. 98:8644-8654.

Wiltbank, M. C., and J. R. Pursley. 2014. The cow as an induced ovulator: Timed AI after synchronization of ovulation. Theriogenology 81:170-185.

Wiltbank, M. C., A. H. Souza, J. O. Giordano, A. B. Nascimento, J. M. Vasconcelos, M. H. C. Pereira, P. M. Fricke, R. S. Surjus, F. C. S. Zinsly, P. D. Carvalho, R. W. Bender, and R. Sartori. 2012. Positive and negative effects of progesterone during timed AI protocols in lactating dairy cattle. Anim. Reprod. 9:231-241. 